\title{
Community Impact of Unconventional gas development: Summary, Challenges and Conceptual Framework
}

\author{
Valentina Ivan ${ }^{1}$ \\ ${ }^{I}$ Faculty of Public Administration and Management, Academy of Economic Sciences, Bucharest, Romania
}

\begin{abstract}
The exploitation of any energy resource produces impacts and bears risks; unconventional natural gas resources are not an exemption. The development of unconventional gas has potential to change local economies and social relations. With the aim to understand the social impact on rural communities experiencing unconventional gas development, researchers have turned towards earlier efforts, in particular of rural sociologists which have developed a robust literature assessing the social and economic impact using mainstream models such as The Boomtown Model, The Social Disruption Boomtown Model, The Natural Gas Development Model, and The Resource Curse Model. The frameworks are instructive and provide a useful starting point for assessing the main social attitudes towards unconventional gas development; however, some assumptions used to fundament the models no longer fit, and more rigorous research and analysis is necessary with the aim to adapt to the new era of energy development. Collecting evidence on the impact of the unconventional natural gas exploitation is still work in progress as the resource has only recently been started to be commercially exploited in the United States.
\end{abstract}

Keywords - shale gas, local community, social impact, boomtown, resource development

\section{INTRODUCTORY REMARKS}

Unconventional natural gas, and in particular shale gas has grown significantly since the 2000s triggered by technological advances which made possible the extraction of resources otherwise difficult to exploit. These resources are perceived unconventional because the natural gas is trapped in geological formations characterized by tiny pockets and fissures and requiring a specific and refined hydraulic fracturing and horizontal drilling techniques. The technological developments that have led to the exploitation of unconventional gas formations can be summarized in three main steps. First, the ability to drill horizontally at high depths has eased access to impermeable rock formations. Horizontal drilling is the process of drilling a well which is initially vertical, but turns horizontally to better reach geologicical formations, thus allowing a single exploratory site on the surface to exploit hydrocarbons from a large area underground. Second, the IT capacity to model has guided drilling operations at high depth to reach pockets of gas. Third, the ability to fracture the rocks so that the gas can flow was the breakthrough technology, the last piece of the puzzle that has lead to the unconventional gas revolution in the United States. The process of fracking or hydraulic fracturing involves injecting a mixture of water, sand and chemicals into a borehole under high pressure to fracture the unconventional gas formations, creating pathways through which oil and natural gas can migrate. Extraction of natural gas from unconventional geological formations, such as shale has reversed a decades-long downward trend in United States and brought new opportunities, leading to substantial benefits, in particular economic and geopolitical, most important is the fact that the United States are moving towards increasing self sufficiency. The production of natural gas from unconventional gas formations has simply rejuvenated the natural gas industry in the United States. The shale gas success has fuelled hopes around the globe, especially for countries dependent on energy imports, countries which are looking for ways to lower energy prices, boost their manufacturing sector, and bring extra revenues to the central budget. Growing energy demands, rising environmental awareness, increasing fossil fuel prices, the desire to decrease dependency from foreign energy, changing political realities and new energy technologies have placed unconventional resources high on governments' agenda and made it an attractive source of supply.

The impact of natural gas production from unconventional gas has led to heavy debate and controversy related to the exploitation technology. Worldwide, there are usually two sides to the debate, one which argues that it could score energy-self sufficiency, while its detractors argue that its development should be avoided as it bears great risks to environment and human health. Others are taking a position that is more cautious and emphasize that these risks should be investigated and safeguarded before more wells are drilled. Debates continue in the scientific, policy arena, local communities and the media about the potential impacts of unconventional gas extraction. Researchers [1] have pushed forward the argument that the debate has typically revolved around potential gains in economics, such as employment and a boost in governments' revenues, 
energy independence, and national security, as well as potential harms to the environment, the climate, and public health. Without exception, the exploitation of any energy resource produces impacts and bears risks. Therefore, in order to make sound decisions about future energy resources, it is of paramount importance to clearly understand the potential impacts, both positive and negative.

Within the social sciences, a growing body of literature has begun to examine the social impacts on communities where natural gas extraction takes place. Researchers have argued that the extraction of unconventional energy through 'fracking' is socially problematic [2]. The objective of this paper is first to review the social impacts associated with unconventional natural gas development based on available literature and provide a tally of most frequently 'claimed' social impacts/risks to be of fundamental support for future research and better understanding of the specific risks associated with the development. First, it reviews main conceptual frameworks provided by literature used to assess the social impacts of exploitation of natural resources (conventional gas, oil, and mining) on local communities and their criticism. The article highlights the main challenges in replicating the frameworks when assessing the impact on local communities undergoing unconventional natural gas development. Second, the social impacts are considered mainly in one direction, adverse impacts and opportunities. The article puts forward a classification of social impacts associated with unconventional natural gas development depending on the development phase of a project. Accordingly, the potential impacts should be grouped according to the development stage for which they are relevant, namely following five stages (a) Site development and drilling preparation; (b) Drilling activities; (c) Fracturing and well completion; (d) Production and operation; (e) Well abandonment and post-abandonment. The article identifies the main challenges when assessing social impacts associated with development of unconventional natural gas resources. Identification of most important challenges is fundamental to the better understanding of specific risks related to unconventional natural gas development.

\section{RESEARCH DESIGN}

The methodology is grounded on systematic reviews of academic literature, as well as the 'gray literature' mainly through Google's search engine. Literature review was carried using established academic databases (Thomson ISI, JStor, ScienceDirect, SpringerLink, Oxford Journals, Taylor \& Francis, WileyBlackwell, Emerald Management Xtra, Scopus, ProQuest - Academic Research Library, Ebsco Academic Search Premier). This has lead to a fully-referenced overview of the main social issues attached to unconventional gas development. Significant challenges were encountered when undertaking this review of this novel topic as some articles failed to stand up to peer-review scrutiny (with some articles exaggerating the magnitude of impacts, both positive and negative). Considering the novelty of the topic it is likely that articles based on robust data sets and spanning longer time periods enabling conclusive remarks will appear about the plays developed in the United States and their impact on local communities in the years to follow. Drawing on research focused mainly on the development of unconventional gas resources in the United States, the article assesses most relevant issues for research and policy makers related to unconventional gas development. The review does not include economic and environmntal impacts of unconventional natural gas on local communities, though most of the articles on the unconventional gas topic address these issues.

Starting the 70s, rural sociologists have employed a variety of methods to gain insight into the social impact of rapid energy development in rural areas, especially in the United States. This paper reviews the four most widely used frameworks to assess the social impacts due to rapid energy related development. The Boomtown Model, The Social Disruption Boomtown Model, The Natural Gas Development Model, and The Resource Curse Model. The conceptual frameworks for assessing the social impact has evolved over time and are now grounded on rigorous, quantitative studies. However, given the novelty of the unconventional gas resources and the lack of robust data sets spanning for longer periods of time, qualitative methods (such as interviews, focus groups in the affected communities, surveys) with the aim to encompass perceptions of the social impacts of energy development on rural communities are widely employed. This begs for a more balanced view, and a more cautious interpretation of the impacts described as some of the articles reviewed are based on the residents' perceptions. These types of effects are difficult to capture and be measured by available data.

The paper addresses answers to two research questions in order to understand social changes that occur in existing communities when unconventional natural gas development becomes a major economic activity. The first question asks which are the main conceptual frameworks provided by literature used to assess the social impacts? Can these models ("The Boomtown Model", "The Social Disruption Boomtown Model", "The Natural Gas Development Model", "The Resource Curse Model"), with attached challenges and criticism be replicated to assess the impact on local communities undergoing unconventional natural gas exploitation. The second questions asks which are the positive and negative social changes as portrayed by literature that occur when unconventional natural gas is developed in local communities? 


\section{CONCEPTUAL FRAMEWORKS ASSESING SOCIAL IMPACTS}

The paper briefly reviews main models as provided by literature, their criticism and point to the main challenges when trying to adapt the model to assessing the social impact of unconventional natural gas development on local communities. The exploitation of any energy resource produces impacts and bears risks; development of unconventional gas resources is not an exemption, moreover, it is a highly contested issue mainly for the uncertainties related to the risks attached (due to the recent exploitation of unconventional natural gas resources in United States after 2000, there are no long term impact studies while evidence on the likely risks is still being collected). The development of unconventional gas has been described [3] as having more potential to change local economies and social relations than any other phenomenon in recent history. With the purpose to understand the social impact on rural communities, researchers have turned towards earlier efforts in particular of rural sociologists which have developed a robust literature assessing the social and economic impact of "boom \& bust" cycle in rural communities ever since the 70s, while others have used the term "boomtown" to refer to towns that experienced rapid natural resource development in isolated, rural communities in the United States (1970s to1980s). The main conceptual frameworks as identified from the literature review and to be addressed are The Boomtown Model, The Social Disruption Boomtown Model, The Natural Gas Development Model, and The Resource Curse Model.

The Boomtown Model was advanced in the 70s [4] and was used to describe socioeconomic changes that are likely to take place due to natural resource extraction on a fast track, in particular extraction of gas, petroleum or coal mining in rural areas. This is the main theoretical approach used to understand social impacts on extractive communities [5] and it was reviewed along the years by several researchers. Boomtowns are places that have experienced rapid economic growth and demographic change, mainly due to natural resource extraction activities [6], [7], [8]. The initiator of the framework [4] did not use however an existing community, but envisaged a fictional rural town facing a sudden influx of population and economic activity due to natural resource extraction. The challenges was summarized in a framework labeled "The Problem Triangle" and portrayed below in Fig. 1.

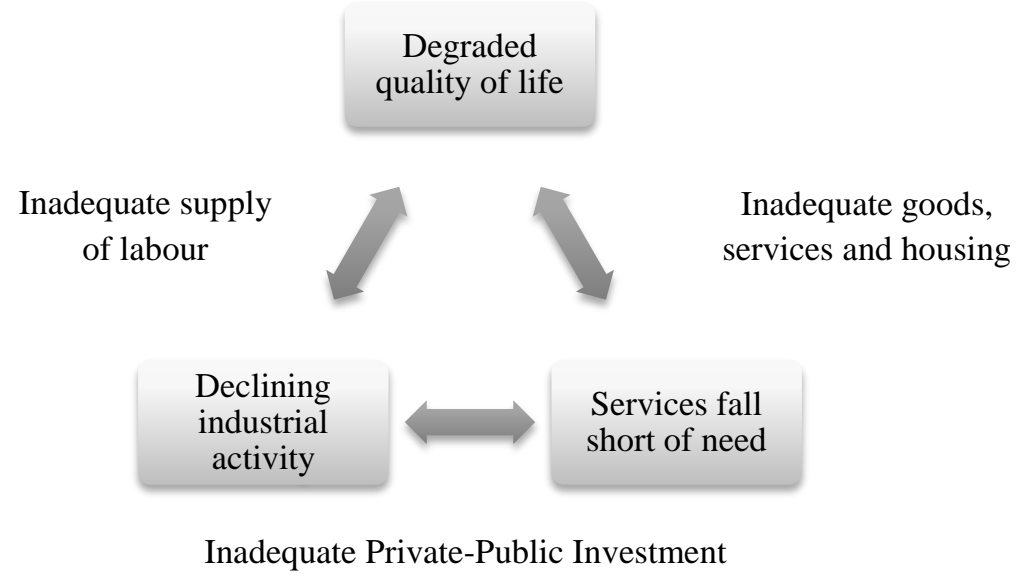

Fig. 1: The Problem Triangle

Source: [4]

The challenges portrayed [4] were split in three main categories. First, these projects were associated with overwhelming population growth causing strain on local services, an increased demand on local police, school, health and social services, as well as housing. Local governments had to deal with pressing and current needs for an unknown future and significant investments had to be directed towards services for which there was no demand before the boom in the natural resource exploitation. Second, [4] boomtowns bring dramatic changes to social structure (such as male predominance), with increased diversity (brought by the newcomers in the community), sometimes conflicts among residents, and increased crime acts and weakened social ties, an overall degradation of quality of life. Finally, the boomtowns bring a declining industrial activity accompanied by an inadequate supply of labor [4] for other economic activities (for example, in an agriculture based community, residents are more likely to be incentivized to change job by the promising wealthier prospects of working for the extractive industry).

The researcher [4] further reviews the community attitudes when rapid natural resource extraction occurs and highlights four stages: (a) enthusiasm - when the community takes notice of the positive socioeconomic benefits as advocated by industry, (b) uncertainty - when the community experiences initial 
negative impacts and acknowledges that situation is likely to worsen, (c) near panic - when the negative impacts of the natural resource extraction deepen, placing significant pressure on the local services and governments which are responsible for supplying these (4) adaption - when main challenges attached to natural resource extraction are mapped out and strategies to mitigate and diminish impact are drafted; at this stage of development, the community accepts the reality and deals with attached opportunities and challenges. The four stages can be replicated in unconventional natural gas projects developed in local communities as well. Enthusiasm could be observed in Europe after 2009-2010, when the benefit of exploiting unconventional gas in the United States were regarded as a success story, with some governments (in particular in United Kingdom and Poland) weighing the economic benefits. Some communities however expressed worries regarding the environmental impact of unconventional gas and some countries (such as France and Bulgaria, Romania in the initial stages), or states (within Germany) voiced against exploration of unconventional gas and pressured the governments into imposing bans and moratoria. Uncertainty followed as the industrial activities related to exploration started to be felt in the local communities (traffic and noise linked to setting up the exploration sites); in the same time, worries were voiced about local government's capability to handle, monitor and regulate a complex and novel issue such as unconventional gas development supplemented by the pressure on the industry to increase transparency in particular related to the likely environmental impacts. The third stage, near panic, was experienced only in few countries which were developing sites on the verge of commercial exploitation. In April 2011 there were small tremors at a site in United Kingdom where hydraulic fracturing operations were taking place. Researcher [9] highlights that the felt seismicity (...) attracted significant public interest worldwide, resulting in a government enquiry and an 18-month suspension of operations. During the investigation, the United Kingdom Department of Energy and Climate Change commissioned three independent experts to assess the causes which concluded that the tremors were probably caused by fracking fluids flowing into a geological fault. This has created a window of opportunity for the United Kingdom government which introduced new controls and checks for operators using hydraulic fracturing and imposed stricter monitoring [10], thus increasing the trust in the authorities. This shows that the near panic stage refers to challenging situations, as well as measures to mitigate or diminish the likely impacts. Europe has not experienced so far (mid 2016) commercial exploitation of unconventional resources, and thus did not reached the last stage, adaptation. Despite all these, the model can be used as a framework to address the main social attitudes towards unconventional gas development in local communities undergoing unconventional gas development and has proved efficient in framing unconventional gas impacts in United States communities undergoing rapid social changes due to development of unconventional natural gas resources.

The Boomtown Model is commonly used to assess boom and bust patterns, but it was criticized mainly for the lack of quantitative data to support qualitative claims [11] which is mainly due to imperfect data collection or inconsistent methodologies [12], over-and-under estimate the socioeconomic impacts [13], [14] while most of the boomtown research was carried along the boom of the resource exploitation, with very few studies being conducted before the peak or after the bust [11]. Despite criticism, the model is instructive and provides a useful starting point for assessing the impact of new energy developments, such as unconventional natural gas development. When implementing the model in local communities where unconventional plays are developed, contextual dissimilarities can be highlighted. Most important, as portrayed by cases in the United States, unconventional gas projects are more ample forms of resource development, sometimes spanning over large landscapes [15]. Unconventional gas plays are located in highly populated areas, which is quite different from the mining projects as portrayed by the boomtown literature, thus increasing the number of residents to bear the risks and the negative impact such as dust, noise and traffic, and likely health issues [16], [17]. Furthermore, the review of the work of the rural sociologist from the 70s shows that their work was grounded on robust data sets spanning over longer time periods. Collecting evidence on the impact on the unconventional natural gas is still work in progress as the resource has only recently been started to be collected in the United States, while in Europe no play has reached commercial exploitation.

Few years later, in 1978, the boomtown model was reframed [18] with an emphasis on community attitudes and local governments' capacity to deal with the limitations linked to natural resource extraction in what was coined as the Social Disruption Boomtown Model. A pattern that is linked to the previous framework was used summarizing six main challenges: (a) jurisdictional unevenness - when the local governments do not have the power to control the development and fully encompass and address issues; (b) conflict between residents, specifically between the new residents versus old residents which are reluctant to change; (c) insufficient control of land use as local governments are ill prepared to address development issues; (d) fast population growth overwhelms public services putting pressure on the local governments to create facilities to supply these public services: from more schools to increased personal dedicated to law enforcement; (e) volatile production patterns linked to the boom and bust cycle that describe the industrial development and in particular natural extraction - at this stage, local governments have to address immediate needs which are likely to prove to be an overcapacity in the near future and (f) monopoly of information which mainly resides at the industry 
level holding information about real risks and benefits, thus having the incentive to misinform. The researcher [18] describes six limitations of local governments when faced with natural resource extraction. First, jurisdictional unevenness in the case of unconventional resources development can be portrayed by the fact that local communities have lost control over the industry. For example, in most of the European countries central governments are the ones granting the industry the licenses to explore, develop and exploit the unconventional gas resource, while in the same time cashing in the revenues from royalties, leaving the local governments to bear the risks for a much lesser gain when compared to the central government. Furthermore, while the industry held the monopoly of information in the beginning, as the pressure from local communities and environmental NGOs increased, the industry and the governments boosted the access to information and increased overall transparency. Insufficient control of land use was claimed by residents in local communities and environmental NGOs [19]. This is mainly due to the fact that the regulatory framework in some of the European countries is not taking into consideration the natural gas development due to the novelty of the topic. A rapid influx in population was not experienced on the European continent in relation to the unconventional gas development as none of the sites currently undergoing exploration works have not reached commercial exploitation. Finally, the consequences of volatile production patterns were not experienced as well. The model has also received criticism for poor data collection and scare longitudinal analysis [11], but despite its flaws, nearly 40 years later the legacy of this research is of key importance for understanding communities undergoing rapid change from energy development such as unconventional natural gas. However, some assumptions used to set up the model no longer fit, and more rigorous research and analysis is necessary with the purpose to fundament a model adapted to the new realities of energy development.

As current technological advancements and unconventional natural gas development have polarized discussions on future natural resource extraction, mainly in US, as well as China, Australia and Europe, the framework was revised [11], [20] with the aim to compare unconventional gas extraction to the patterns provided by The Boomtown Model. Thus, The Natural Gas Development Model was framed [11] and divided in four phases of natural gas development: (1) the pre-development phase, which is the moment when the industry receives the license from the central government to explore potential for unconventional gas resources and starts to investigate the targeted region; (2) the development phase which is perceived to be short lived and very labor intensive; at this stage, the industrial activity in the area increases with the construction of the wells accompanied by a large influx in population, infrastructure works (to ease access to the well pads); 3) the production phase is long lived and needs only a reduced number of qualified personnel which are responsible for the extraction works; and 4) the reclamation phase comprises decommissioning works, wells are dismantled and the land is reclaimed. The main criticism to the model is that it mostly focuses on the impact at the macro level, and in particular assessing the economic impact, ignoring impact on local communities and governments [11]. This streamlines the idea that assessing the impact of unconventional gas resources needs a multidisciplinary approach, taking into consideration a mix of social, economic and fiscal consequences, both positive and negative impacts.

The Resource Curse Model was advanced [21], [22] and was triggered by the search for best practices of resource extraction. Researchers have argued that investment in human capital is of key importance for sustainable economic growth. Especially for regions undergoing rapid economic growth due to natural resource extraction, this is of paramount importance to offset the loss in natural capital by investing in human capital. In particular, revenues to the local budget from the extraction of natural resources which sometimes are collected only for a short, booming period should be directed towards longer term costs such as education and training, as well as infrastructure [21], [22]. The Resource Curse framework seen in Fig. 2 below displays a boom and bust cycle, with attached risks.

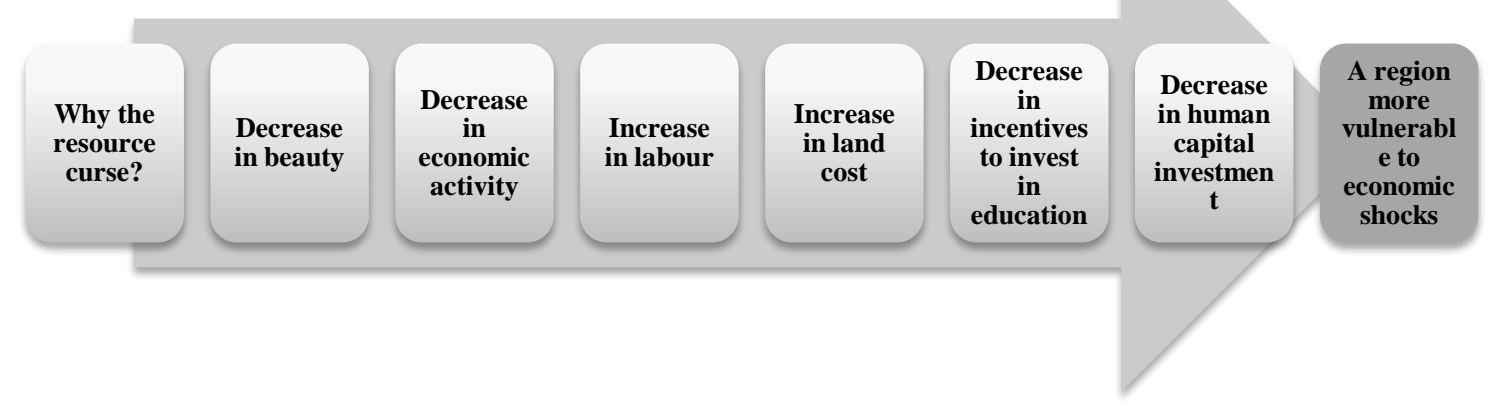

Fig. 2: The Resource Curse 
Source: 21

The risks portrayed by the Resource Curse Model highlight the main challenges brought by the social impact, that a community dependent on one economic activity (in this case unconventional gas development), one that portrays peaks and lows, creates a vulnerable community. The exposure is likely to come from the fact that a community undergoing rapid industrial development loses its beauty; furthermore, industries or economic activities not related to the resource extraction industry may be harmed (due to the competition for resource, from land to labor force). Other researchers, building on more robust data sets, for example over a decade or scanning nine state-regions [23], [24] argue that the economic activity associated with drilling, such as increases in employment and population attached to the fracking energy boom have overall positive effects, while others have difficulties in finding a clear validation of the resource curse theory [25], [26], [27].

The first question addressed by the article aimed to identify the conceptual frameworks which can be used when trying to assess the social impact of unconventional gas development. The paper has reviewed four main frameworks: "The Boomtown Model", "The Social Disruption Boomtown Model", "The Natural Gas Development Model”, "The Resource Curse Model”. The models reviewed are instructive and provide a useful starting point for assessing the impact of new energy developments such as exploitation of unconventional gas. Furthermore, the paper aimed to identify whether these models with attached challenges and criticism can be replicated to assess the impact on local communities undergoing unconventional natural gas exploitation. The framework used to assess the impact of oil, gas and mining projects on rural communities faces differnt contexts when applied to unconventional gas developments such as the fact that this projects are manly located in densely populated areas, thus we are referring to a larger number of resident being affected. The body of evidence tended to find a mix of positive and negative social impacts (with predominance of adverse effects). Further research is needed to carry new theoretical and empirical assessments and shape a framework.

\section{ASSESSMENT OF THE SOCIAL IMPACT OF UNCONVENTIONAL GAS}

Literature is vast in portraying the environmental and economic impact of hydraulic fracturing; however it has disregarded the impact on daily life in the communities where it occurs [28]. The negatives portrayed by the literature can be coined with mainstream terms such as 'resource curse', showing that the discovery of resources from unconventional gas formations have lead to more costs that benefits (or rather small benefits) for the nearby communities; or by the 'boom and bust cycle' phrase showing that unconventional gas has triggered a rapid expansion, followed by a steep decline and a significant number of challenges which have to be dealt with by a vulnerable community. The social benefits of unconventional shale gas development include job creation and low unemployment, a stimulated local economy and an increase in demand in services such as restaurants, hotels and bars; a rise in per capita income; an increased population; increase in local businesses' revenue; and increase in tax revenue. Unconventional natural gas is often perceived as having a negative impact on communities. Overall residents' quality of life is negatively impacted, as well as community cohesion. Individuals residing in communities where shale gas production was taking place believed that disagreements among inhabitants were increasing due to natural gas drilling [16]. Newcomers into local communities also lead to social disruption and sometimes altering previously informal social and economic relationships and forcing community members out of their social roles or disrupting cultural values and identities [11]. These more subtle effects on mental health, identity, and community are receiving less attention than, for example economic and environmental impact and impacts over long-term are uncertain. In comparison with impacts on property value or on air emissions, which can be measured, the subtle effects associated with the social impact are more difficult to quantify.

The paper will proceed to reviewing the main social impacts on local communities attached to unconventional gas development based on literature review with the aim to address the second research question of this paper, a layout of the main adverse impacts following each stage of development. The Site development and drilling preparation phase encompasses activities required to set up the well-pads. This is accompanied by a strain on infrastructure, in particular on roads needed to reach the development site (to install equipment, to bring and take workers to and from the site). The stage also requires building pipelines and storage facilities. The early stages of unconventional gas development involve different tests being carried (seismic ones, tests to evaluate the commercial viability of the resources which require hydraulic fracturing and thus a large quantity of water, as well as disposed water to be transported to and from the operation site). At this stage, disturbance derives from increased traffic and noise in their community. The water is transported by trucks, thus raising concerns about noise, road damage and accidents due to increased traffic [29], [30]. These externalities can be managed by the operator and the local government with the aim to minimize disruption for the residents. Traffic can become troublesome and sometimes can lead to congestions and even traffic accidents and can deteriorate the local infrastructure and require significant investments from the local budget to be directed towards refurbishing the roads. When taking into consideration the impact of truck traffic, a wider picture should be 
envisaged, as it involves not only the traffic around a well pad, but a broader range of effects dispersed around the community, including exposure to exhaust, vibration, and dust, and safety risks. At this stage the operators, the companies interested to explore the potential of unconventional natural gas resources want to secure the land, the sweet spots which are likely to hold resources. In the United States companies were leasing the land from individuals thus, leading to an increase in the personal wealth of the residents. The amount of land required by unconventional gas development depends, amongst others on well pad density and size, number of wells per pad. Things are however different between the United States and Europe. One of the most important plays in the United States for exploitation of unconventional gas resources, Marcellus shale is located in a highly populated area (as compared to Texas, another important extraction area), over Pennsylvania state, a population density of $107.24 / \mathrm{km}^{2}$ [31] while some European countries have a higher population density (UK, 262/ $\mathrm{km}^{2}$,

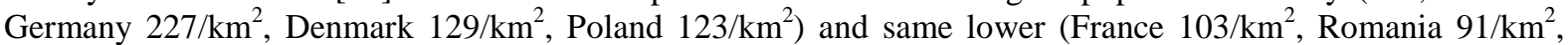
Bulgaria $62 / \mathrm{km}^{2}$, Sweden $22 / \mathrm{km}^{2}$ ). Furthermore, the European landscape is more fragmented, with smaller landholdings for farming [32]. Experience in the United States shows that negotiation with several landowners increases costs, sometimes leading to delays in the project and social disruption. Here, the landowners entered in a pooling so that several pieces of land belonging to several owners came together to support development of a well pad [33]. The scholars draw attention to the fact that this approach has reduced costs with infrastructure, and timeline to get approvals. The United States regime of ownership of subsoil mineral rights, with direct material incentives being granted to the landowner improves social acceptability of unconventional gas projects. This is different than most of European landowners that do not own subsoil mineral rights. Furthermore, collecting revenues from gas production to the central budget and not to the local communities is a 'take one for the team' case, asking the local communities to bear the risks while not enjoying the benefits. Review of social aspects related to unconventional gas has shown that the lack of material incentive is likely to be only one of the deterrents to social acceptability, with some landowner more interested to have a say in the permitting process, than receiving money. Potential landscape fragmentation and conflicts with other land users are likely to appear. For example, it is likely that the main economic activities in the area (tourism, or agriculture - arable land, pasture of forest) are likely to be affected; competition for land use leaving room for associated conflicts. The issue is relevant for the residents (local farmers) considering that the site requires also a minimum distance the farmers may wish to keep from the well. Deterioration of landscape is likely to lead to decrease in tourism activities or a move away from conventional activities in that respective area. The beauty of a landscape contains instrumental value with economic implications which are difficult to assess. Researchers [34] have highlighted that agriculture is one of the main activities to be impacted in local communities, especially the ones heavily dependent on it. First, hydraulic fracturing technology requires large volumes of water which can cause farmers to focus only on crops requiring less irrigation or not at all. Second, heavy traffic brings a lot of dust which can have a negative impact on the productivity of the crops. Third, the higher salaries in the extractive industries can be an incentive for the low skilled workers to leave their job in agriculture for a job at the extraction site, thus increasing the labor costs for the agriculture sector. Moreover, at this stage positive prospects for increased employment rate ale likely to appear. The paper treats the jobs opportunity and the increase in individual's wealth and increased spending as being linked more to the economic impact of the development of unconventional gas and disregards the benefit from the analysis.

The drilling phase in unconventional gas development is performed using similar equipment and technology as vertical drilling, plus employment of a high-volume hydraulic fracturing. The technology requires significant quantities of fracturing fluid being pumped into the well at high pressure. After the hydraulic fracturing procedure is completed and pressure is released, the direction of fluid flow reverses, resulting in wastewater which has to be disposed or recycled. The activity poses pressure on the local infrastructure, in particular on the municipal sewage treatment facilities if this is the option taken into consideration by the operators which could also opt for reuse of water or treatment in industrial plants. Before the start of the production phase, pipeline infrastructure must be developed to collect natural gas and transfer it to the existing natural gas pipeline. When the well is no longer economic to operate, it is taken out of service (temporarily or permanently). Abandonment phase takes place in accordance with established procedures in the oil and gas production industry. The paper will further address the main social issues attached to the drilling and production activity. First, a rapid population growth, of about $10-15 \%$ per year is recorded in one of the communities where unconventional gas development was taking place accompanied by an afflux of workers [28]. This changes population demographics in local communities, with male-majority populations, individuals that have a low attachment to the local hosting community. Second, population growth further creates pressure on the housing, human services, health services, schools, and social services. At this stage, local governments often feel ill prepared to deal with a significant boost in demand for public services and is obliged to allocate funds from the local budget to service the needs. Researchers [35] have analyzed the capability of the governments to deal with the rapid changing conditions and have showed that, for example phone calls to police increased by over $33 \%$ in Pennsylvania energy producing counties between 2006 and 2010. Rapid population changes (derived from the 
workers on the industrial site accompanied by their families) can put more pressure on local schools, which in small communities cannot accommodate the needs. Others [36] have found however found that school in the affected counties in Pennsylvania did not experience a net increase in enrollment associated with unconventional gas development. This can be explained by the fact that most of the workers on the drilling sites do not bring their family to live with them in the proximity of the operation site. Workers on the operation site require housing facilities, with some being addressed by the companies performing the operations who build dormitories for the workers [36], but this fails to meet the demand, putting pressure on the local services. A lack of affordable, quality housing has been identified as one of the most critical early impacts unconventional gas development in the United States, especially in small rural communities [5]. Furthermore, a decrease in property value has also been documented with proof of decrease in prices of about $5.6 \%$ between 2008 and 2010 within a mile of a well pad [37]. Other researchers [38] analyzed the impact of property prices in Pennsylvania, within a mile of gas wells between 2004 and 2009 and revealed a positive price effect. Overall the evidence on impact on property prices in the literature is quite thin and the results are not conclusive. Third, researchers [5] have shown a negative impact on individuals' quality of life, community cohesion and disagreements among inhabitants were worsening due to unconventional natural gas drilling and the newcomers were found to alter social structures such as cultural ties. They were perceived by the resident as transients and were reluctant to engage with them. Social disruption was documented to affect quality of life and pose other risks to physical and mental health [39]. Finally, demographic changes and population growth is likely to fuel crime especially considering the influx of young males can further perpetuate the problem. A study [40] canvassing 8 local communities undergoing unconventional natural gas development and using multiple data sources (official crime statistics, census data) and interviews with 101 sworn police personnel found that rapid population expansion can result in elevated levels of fear of crime and an increase in crime rates (such as forcible rape, aggravated assault, robbery, larceny and murder); however, the results are only moderately robust.

The paper aimed to address another research question, which was to provide a review of the negative impacts accompanying the main stages of the unconventional gas development. It has found that a significant number of challenges are encountered by vulnerable local communities: pressure on the local infrastructure, overall residents' quality of life is negatively impacted, as well as community cohesion, disturbance to the local residence (deriving from increased traffic and noise), a rapid population growth accompanied by an afflux of workers, potential landscape fragmentation and conflicts with other land users. The empirical evidence is however lacking and most of the studies are qualitative. The main challenge in this respect is that social impacts are not as easy to identify and quantify as economic and environmental impact and impacts over long-term are uncertain.

\section{CONCLUSION AND FORWARD LOOKING}

The narratives reviewing the main social impacts attached to unconventional gas have showed that scientific conclusions have not yet been drawn for some risks while for others, there are different views. The starting point for a socially sustainable unconventional gas development is the understanding of impacts, risks and uncertainties of unconventional gas development. Fracking for unconventional gas is a novel topic and there are still gaps in the scientific literature regarding the magnitude of its impacts and the topic is still surrounded by a high degree of uncertainty. When taking decision, policy makers will need to encompass and treat the uncertainties consistently. The challenge today is that we live in complex systems, but we do not understand complexity of the systems we live in. Unconventional gas (hydraulic fracturing) is an emerging technology which bears multidimensional impacts (environmental, social, economic), scientific uncertainty (due to novelty of the topic, different views on the risks and benefits entailed), incomplete understanding of phenomena which breads suspicion and mistrust leading to social disruption and challenges to the risk governance. This is why, unconventional gas framing needs a trans - disciplinary approach, a multi-method and multi-stakeholder approach, able to match energy policy objectives, risk and uncertainty governance approaches while involving stakeholders with the final aim to mitigate and diminish environmental impact, boost social sustainability and economic contribution. Research should be directed towards more multidisciplinary assessments on the societal costs of unconventional natural gas extraction with the aim to reassess the validity of models used to assess the socio economic impacts and provide best practices to help governments shape regulatory framework. As social impacts are difficult to pin down, it should be supplemented by surveying community members' perception on the positive and negative impacts, as well as qualitative data spanning longer time periods; researchers should consider going beyond the models advanced by early rural sociology literature and provide insight into opposition and conflict that arises in local communities and identify effective mechanisms for public engagement.

\section{ACKNOWLEDGEMENTS}


This paper was co-financed from the European Social Fund, through the Sectorial Operational Programme Human Resources Development 2007-2013, project number POSDRU/159/1.5/S/138907 "Excellence in scientific interdisciplinary research, doctoral and postdoctoral, in the economic, social and medical fields EXCELIS", coordinator The Bucharest University of Economic Studies.

\section{REFERENCES}

[1] I. de Melo-Martín, J. Hays, and M.L. Finkel, The role of ethics in shale gas policies, Science of the total environment, 470, 2014, 1114-1119.

[2] C. Kerschner, C. Prell, K. Feng, and K. Hubacek, Economic vulnerability to Peak Oil, Global Environ. Change, 23(6), 2013, 1424-1433.

[3] R.C. Stedman, J.B. Jacquet, M.R. Filteau, F.K. Willits, K.J. Brasier, and D.K. McLaughlin, Marcellus Shale Gas Development and New Boomtown Research: Views of New York and Pennsylvania Residents, Environmental Practice, 14(4), 2012, 382-393.

[4] J.S. Gilmore, Boomtowns May Hinder Energy Resource Development, Science, No 191, February Issue, 1976, 535-540.

[5] K.J. Brasier and M. Filteau, Community Impacts of Shale-Based Energy Development: A Summary and Research Agenda, in M.L. Finkel (Ed.), The Human and environmental impact of fracking: how fracturing shale for gas affects us and our world, (Santa Barbara, California: Praeger, 2015), 95-114.

[6] R. Brown, S. Dorius, and R. Krannich, The boom-bust-recovery cycle: Dynamics of change in community satisfaction and social integration in Delta, Utah, Rural Sociology, 70, 2005, 28-49.

[7] A. Kinchy, S. Perry, D. Rhubart, R. Stedman, K. Brasier, and J. Jacquet, New natural gas development and rural communities: Key issues and research priorities, in C. Bailey, L. Jensen, and E. Ransom (Ed.), Rural America in a globalizing world, (Morgantown, WV: West Virginia University Press, 2014), 260278.

[8] R.R. Perdue, P.T. Long and Y.S. Kang, Boomtown Tourism and Resident Quality of Life: The Marketing of Gaming to Host Community Residents, Journal of Business Research, 44(3), 1999, 165-177.

[9] P. Styles, Shale Gas and Hydraulic Fracturing: A Review of the Environmental, Geological, and Climate Risks, The Emirates Center for Strategic Studies and Research, 2015, 299-346.

[10] C.M. Profiroiu, P. Gasparini, and V. Ivan, Uncertainty in the Shale Gas Debate: Views From the Science-Policymaking Interface, Transylvanian Review of Administrative Sciences, 11(46), 2015, 144161.

[11] J.B. Jacquet and D.L. Kay, The unconventional boomtown: Updating the impact model to fit new spatial and temporal scales, Journal of Rural and Community Development, 9(1), 2014, 1-23.

[12] A.N. Hall, Socioeconomic Impacts of Natural Gas Extraction in Bradford County, doctoral diss., University of Cincinnati, US, 2015.

[13] T.C. Kinnaman, The economic impact of shale gas extraction: A review of existing studies, Ecological Economics, 70 (7), 2011, 1243-1249.

[14] D. West, T. Knipe, and S. Christopherson, Frack or bust, Planning, 78 (4), 2012, 8-13

[15] R.C. Stedman, J.B. Jacquet, M.R. Filteau, Environmental reviews and case studies: Marcellus Shale gas development and new boomtown research: views of New York and Pennsylvania residents, Environmental Practice, 14, 2012, 382-393.

[16] G.L. Theodori, Paradoxical perceptions of problems associated with unconventional natural gas development, Southern Rural Sociology, 24(3), 2009, 97-117.

[17] T. Colborn, C. Kwiatkowski, K. Schultz, and M. Bachran, Natural gas operations from a public health perspective, Human and ecological risk assessment: An International Journal, 17(5), 2011, 1039-1056.

[18] A.R. Markussen, Socioeconomic Impact Models for Boomtown Planning and Policy Evaluation, Presented at the Western Regional Science Association Meetings, February 25, 1978, Sacramento, CA.

[19] European Commission, Directorate General Environment, Study on the regulatory provisions governing key aspects of unconventional gas development in eight Member States, Milieu Ltd, 2013.

[20] M.A. Heuer, and C.L. Zui, Marcellus Shale Development and the Susquehanna River: An exploratory analysis of cross-sector attitudes on natural gas hydraulic fracturing, Organization \& Environment, 27(I), 2014, $25-42$

[21] D.E. Albrecht, Our energy future: Socioeconomic implications and policy options for rural America (London: Routledge, 2014).

[22] J. L. Pender and J. G. Weber, Sustainable rural development and wealth creation: Five observations based on emerging energy opportunities, Economic Development Quarterly, 28(I), 2014, 73-86.

[23] J.G. Weber, A Decade of Natural Gas Development: Making of a resource curse?, Resource and Energy Economics, 37, 2014, 168-183. 
[24] J.P. Brown, Production of Natural Gas From Shale in Local Economies: A Resource Blessing or Curse?, Economic Review, 99(1), 2014, 5-33.

[25] R. Torvik, Why do some resource-abundant countries succeed while others do not?, Oxford Review of Economic Policy, 25(2), 2009, 241-256.

[26] G. Michaels, The long term consequences of resource-based specialization, The Economic Journal, 121(551), 2010, 31-57.

[27] A. James, and D. Aadland, The curse of natural resources: an empirical investigation of U.S. counties, Resource and Energy Economics, 33(2), 2011, 440- 453.

[28] B.J. Anderson, and G.L. Theodori, Local leaders' perception of energy development in the Barnett Shale, Southern rural sociology, 24(1), 2009, 113-129.

[29] J. Gilman, B. Lerner, W. Kuster, and J. de Gouw, Source Signature of Volatile Organic Compounds from Oil and Natural Gas Operations in Northeastern Colorado, Environmental Science and Technology, 47(3), 2013, 1297-1305.

[30] R.Z. Witter, L. McKenzie, K.E. Stinson, K. Scott, L.S. Newman, and J. Adgate, The use of health impact assessment for a community undergoing natural gas development, American journal of public health, 103 (6), 2013, 1002-1010.

[31] World Atlas, Population density at 2012 - 2014 level, online at http://www.worldatlas.com/aatlas/populations/ctypopls.htm, accessed on July $7^{\text {th }}, 2016$.

[32] T. Spencer, O. Sartor, and M. Mathieu, Unconventional wisdom: an economic analysis of US shale gas and implications for the EU, Studies 02/14, 2014.

[33] I. Pearson, P. Zeniewski, F. Gracceva, P. Zastera, C. McGlade, S. Sorrell, J. Speirs, and G. Thonhauser, Unconventional gas: potential energy market impacts in the European Union, Joint Research Centre of the European Commission, Petten, The Netherlands, 2012.

[34] C. Hitaj, A. Boslett and J.G. Weber, Shale Development and Agriculture. Choices, 29 (4), 2014, 1-7.

[35] L. Kowalski, and G. Zajac, A Preliminary Examination of Marcellus Shale Drilling Activity and Crime Trends in Pennsylvania, University Park, PA: Justice Center for Research, 2012.

[36] K. A. Schafft, B. Yetkin and G. Leland, The relationship between Marcellus shale gas development in Pennsylvania and local perceptions of risk and opportunity, Rural Sociology, 78 (2), 2013, 143.

[37] S. Gopalakrishnan, and H.A. Klaiber, Is the shale energy boom a bust for nearby residents? Evidence from housing values in Pennsylvania, American Journal of Agricultural Economics, 96(1), 2014, 43-66.

[38] L. Muehlenbachs, E. Spiller, and C. Timmins, Shale Gas Development and Property Values: Differences across Drinking Water Sources, NBER Working Paper, Number 18390, 2012.

[39] R.C. Stedman, J. Jacquet, M. Filteau, F. Willits, K. Brasier, D. McLaughlin, Marcellus Shale Gas Development and New Boomtown Research: Views of New York and Pennsylvania Residents, Environ. Pract, 14, 2012, 382-393.

[40] C.A. Archbold, Established-Outside Relations, Crime Problems, and Policing in Oil Boomtowns in Western North Dakota, Criminology, Criminal, Justice Law \& Society, 16(3), 19-40. 